Utah State University

DigitalCommons@USU

1999

\title{
The Stability of Stochastic Systems: The Case of Persistence and Resilience
}

Amitrajeet A. Batabyal

Utah State University

Hamid Beladi

Follow this and additional works at: https://digitalcommons.usu.edu/eri

\section{Recommended Citation}

Batabyal, Amitrajeet A. and Beladi, Hamid, "The Stability of Stochastic Systems: The Case of Persistence and Resilience" (1999). Economic Research Institute Study Papers. Paper 167.

https://digitalcommons.usu.edu/eri/167

This Article is brought to you for free and open access by the Economics and Finance at DigitalCommons@USU. It has been accepted for inclusion in Economic Research Institute Study Papers by an authorized administrator of DigitalCommons@USU. For more information, please contact digitalcommons@usu.edu.

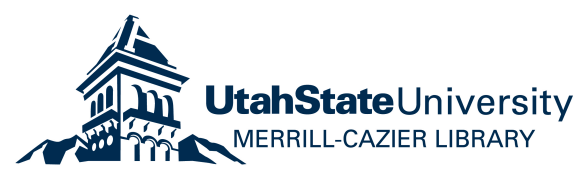


Economic Research Institute Study Paper

ERI \#99-17

\title{
THE STABILITY OF STOCHASTIC SYSTEMS: THE CASE OF PERSISTENCE AND RESILIENCE
}

\author{
by \\ AMITRAJEET A. BATABYAL \\ Department of Economics \\ Utah State University \\ 3530 Old Main Hill \\ Logan, UT 84322-3530 \\ HAMID BELADI \\ Department of Economics and Finance \\ University of Dayton \\ 300 College Park \\ Dayton, OH 45469-2241
}

May 1999 


\title{
THE STABILITY OF STOCHASTIC SYSTEMS: THE CASE \\ OF PERSISTENCE AND RESILIENCE
}

\author{
Amitrajeet A. Batabyal, Assistant Professor \\ Department of Economics \\ Utah State University \\ 3530 Old Main Hill \\ Logan, UT 84322-3530
}

Hamid Beladi

Department of Economics and Finance

University of Dayton

300 College Park

Dayton, OH 45469-2241

The analyses and views reported in this paper are those of the author(s). They are not necessarily endorsed by the Department of Economics or by Utah State University.

Utah State University is committed to the policy that all persons shall have equal access to its programs and employment without regard to race, color, creed, religion, national origin, sex, age, marital status, disability, public assistance status, veteran status, or sexual orientation.

Information on other titles in this series may be obtained from: Department of Economics, Utah State University, 3530 Old Main Hill, Logan, Utah 84322-3530.

Copyright (C) 1999 by Amitrajeet A. Batabyal and Hamid Beladi. All rights reserved. Readers may make verbatim copies of this document for noncommercial purposes by any means, provided that this copyright notice appears on all such copies. 
THE STABILITY OF STOCHASTIC SYSTEMS: THE CASE

OF PERSISTENCE AND RESILIENCE

Amitrajeet A. Batabyal and Hamid Beladi

\begin{abstract}
Beginning with the seminal work of K. J. Arrow and L. Hurwicz, there now exists a vast literature in economics on the stability of economic systems. This notwithstanding, to the best of our knowledge, the economics literature does not contain any studies of the stability of jointly determined, stochastic ecological-economic systems. Consequently, the objective of this paper is to identify and mathematically characterize two stability concepts for such systems.

Key words: persistence, resilience, stability, stochastic ecological-economic system
\end{abstract}




\section{THE STABILITY OF STOCHASTIC SYSTEMS: THE CASE OF PERSISTENCE AND RESILIENCE ${ }^{1}$}

\section{INTRODUCTION}

Beginning with the seminal work of Arrow and Hurwicz [1], there now exists a vast literature in economics on the stability of economic systems. In particular, in the context of economic systems, researchers have spent a considerable amount of time studying the many meanings of stability. For instance, Hirota [2] has addressed the global stability of a class of markets in which there are three commodities and three consumers. Jordan [3] has analyzed the stability properties of nonstationary overlapping generations equilibria. Mitra et al. [4] have studied aspects of the global asymptotic stability of the orchards model of forest management. ${ }^{2}$ Finally, Balasko and Royer [5] have studied the stability of competitive equilibrium with respect to recursive and learning processes.

Despite this great interest in studying the stability of economic systems, to the best of our knowledge, economists have not studied the stability of stochastic ecological-economic systems (hereafter called ecosystems). This is surprising because the study of the stability of ecosystems is mathematically quite challenging. Moreover, in recent times, a number of economists, such as Dasgupta [6], have commented on the significance of studying ecosystems thoroughly.

\footnotetext{
${ }^{1}$ Batabyal acknowledges financial support from the Faculty research Grant program at Utah State University and from the Utah Agricultural Experiment Station, Utah State University, Logan, UT 84322-4810, by way of grant UTA 024. Approved as journal paper \#6050. We thank two anonymous referees and seminar participants at the University of Tennessee-Knoxville, and at the 1999 Annual Meeting of SRIEG 70 for comments. The usual disclaimer applies.

${ }^{2}$ The orchards model is an economic model in the following sense: trees are viewed as capital goods that yield a flow of output over their lifetimes. Because all capital goods age and ultimately die out, the orchards model can be viewed as a framework for analyzing the optimal replacement policy and the age composition of capital goods in a firm or in the economy.
} 
The first aspect of ecosystem stability that we wish to address in this paper concerns the relationship between the number of species in the ecosystem and its stability. In an early study, Elton [7, pp. 145-53] argued that reduced species diversity would lead to decreased ecological stability. Since then, McNaughton [8] and King and Pimm [9] have produced evidence in support of Elton's hypothesis. However, May [10] showed that population dynamics were progressively less stable as the number of competing species in an ecosystem increased. This led May [10] to conclude that there need not be any relationship between diversity and stability. There has been continuing debate in the ecology literature about this "diversity/stability" hypothesis, and theoretical and empirical ecologists disagree on the question of whether an increase in the number of species increases or decreases stability. However, recent research on this topic suggests that a resolution of this issue may be near. Tilman [11] has claimed that whether or not species diversity increases stability depends on whether one is looking at stability at the level of individual species or stability at the level of communities and ecosystems. Tilman [11, p. 361] contends that species diversity increases the stability of communities and ecosystems and "is weakly associated with lower stability of abundances of individual ... species ...."

The second aspect of ecosystem stability that will occupy our attention in this paper relates to the fact that such systems are jointly determined. What this means is that the dynamics of the joint system reflect the nature of the connections between each of the two subsystems, i.e., the ecological and the economic subsystems. Consequently, as Perrings [12] has noted, shocks to the joint system generate a set of ecological and a set of economic effects, and these effects are interlinked. The extent to which these interlinked effects affect the stability of the joint system depends on the degree to which the two subsystems are "connected." Highly connected systems 
coevolve. Consequently, as compared to loosely connected ecosystems, the stability of highly connected ecosystems is more likely to be affected by ecological and/or economic shocks.

In this paper, we shall incorporate the above two aspects of ecosystem stability in our analysis. Because stability has many meanings in economics as well as in ecology, in what follows, we shall focus on two widely known stability concepts from ecology that are particularly relevant to our study of ecosystem stability. These are the concepts of persistence and resilience. Persistence refers to "how long a variable lasts before it is changed to another value . .." [13, p. 14], and resilience refers to "the amount of disturbance that can be sustained [by an ecosystem] before a change in system control or structure occurs" [14, p. 50]. We focus on these two concepts because, in addition to the fact that they are widely known in ecology, persistence, and particularly resilience, have come to dominate much of the present center stage of academic debate about conservation related issues. $^{3}$

The reader may be wondering about the relationship between extant studies of persistence and resilience in the ecology literature and the objectives of this paper. Although there exists a large literature in ecology on resilience and related concepts (see [20]-[22]), most of this literature has focused on the characterization and measurement of resilience in deterministic systems. Commenting on this state of affairs, Ives [23, p. 217, emphasis added] has noted that in order "[t]o apply generally to ecological communities, stability needs to be defined for stochastic systems in which environmental perturbations are continuous and equilibrium [population] densities are never achieved." Further, even in this ecology literature, there do not appear to be any attempts to

${ }^{3}$ For a more detailed corroboration of this claim, see [15]-[19]. 
characterize persistence and resilience in a way that highlights the relationship between species numbers and ecosystem stability.

This review of the economics and the ecology literatures yields three conclusions. First, the stability of stochastic ecosystems has not been studied in economics previously. Second, while persistence and resilience have been analyzed at some depth in ecology, most of this analysis has been conducted for deterministic systems. Third, neither the economics nor the ecology literatures have explored the relationships between persistence, resilience, and the number of species in an ecosystem. Consequently, let us now proceed to mathematically characterize these two stability concepts.

\section{THE PERSISTENCE AND RESILIENCE OF STOCHASTIC ECOSYSTEMS}

\section{2a. Preliminaries}

As Hahn $[24$, p. 747$]$ has noted, most of the economics literature on stability has used difference or differential equations to model the dynamics of the underlying economic system. However, because we are interested in studying stochastic ecosystems, we shall use renewal theory (see [25, particularly pp. 89-92] and [26, particularly pp. 123-32]) to characterize ecosystem persistence and resilience.

Consider a stylized, stochastic ecosystem which consists of $n$ species, where $n \in \mathbb{N}$. The stability of an ecosystem typically depends on the existence of certain key species. Consequently, these keystone species are very important to the functioning of the ecosystem. Suppose that of the $n$ ecosystem species, $m$-where $m<n$ and $m \in \mathbb{N}$-are independent keystone species. Without loss 
of generality, we shall abstract away from the remaining $(n-m)$ species and focus on these $m$ keystone species.

Economic activities such as fishing, grazing, and hiking result in shocks to this ecosystem. Particularly intense shocks will result in the death of one or more of these species. With regard to death, we have two cases in mind. In the first case, species numbers have dwindled to such an extent that preventive policy measures such as regulations on the nature of fishing equipment and moratoriums on grazing are put in place to ensure that literal death does not occur. In this case, we shall say that the affected species are endangered. In the second case, some species may become extinct. Here, we suppose that an ecosystem manager introduces this (now locally extinct) species into our ecosystem from some other ecosystem. ${ }^{4}$ This ecosystem manager pays particular attention to the unique species of the ecosystem. Unique species can be endangered, but they are not allowed to become extinct. The reader should note that all subsequent references to death include both these cases.

There will generally exist some substitutability between species in the performance of ecological functions. Hence, we will need to make an assumption about the degree of this substitutability. The cases of zero substitutability and partial substitutability between species have been analyzed by Batabyal ([17], [27]). Consequently, in this paper we shall study the case of perfect substitutability. In particular, we shall say that at time $t$, our ecosystem is functional, i.e., able to provide a flow of services to society, if at least one of the $m$ species is alive. This means that our ecosystem's stability depends on the survival of at least one keystone species in a fundamental way.

${ }^{4} \mathrm{Here}$, we are referring to the species introduction literature. For additional details, see [13, chapter 15]. 
Now suppose that, as a result of the shocks to this ecosystem from the continuance of economic activities, the $i t h$ species, $i \in[1, m]$, alternates between life and death in accordance with an exponential alternating renewal process. Specifically, suppose that the ith species, $i \in[1, m]$, is alive for a time with distribution function $F(\cdot)$, and that it is dead for a time with distribution function $G(\cdot)$. Let $\alpha$ and $\beta$ denote the means of these two distribution functions. The death times of the various species are stochastic because the rate at which species regenerate or recuperate is generally a stochastic function of environmental variables and the preventive policy measures that have been put in place by the ecosystem manager.

Let us now specify three sets of expectations that we will need to determine the persistence and the resilience of our ecosystem. As indicated in Figure 1, at any arbitrary point in time, the ecosystem is in one of two possible states. These two states are the "breakdown" state and the "functional" state. The amount of time the ecosystem spends in the breakdown state is the length of a breakdown period. We shall be interested in the expected amount of time during which our ecosystem is in the breakdown state. Call this expectation E[length breakdown period]. The amount of time during which our ecosystem is functional corresponds to the length of a functional period. Let the expectation of this time period be E[time ecosystem functional $]$. Finally, as shown in Figure 1, denote the expectation of the time between the beginning of two consecutive breakdown periods by $E$ [time betwixt breakdowns]. The reader should note that $E$ [time betwixt breakdowns] $=E[$ length breakdown period $]+E[$ time ecosystem functional $]$. Let us now determine the persistence of this ecosystem. 
Breakdown

Functional

Breakdown

Length of Breakdown Period E[length breakdown period]

|----Time Ecosystem Functional----|---->Time Axis E[time ecosystem functional]

-Time Between Breakdowns

-> Time Axis E[time betwixt breakdowns]

Figure 1. Time line of events in the ecosystem.

\section{2b. Persistence}

As indicated in section 1, persistence refers to "how long a variable lasts before it is changed to a new value..." [13, p. 14]. This definition tells us that persistence is measured in time units. In the context of our stylized ecosystem, this translates into the time during which the ecosystem is functional. We can now state

Theorem 1. Ecosystem persistence is given by E[time ecosystem functional $]=$ $\left[1-\Pi_{\Gamma=n}^{\lrcorner}\left\{\beta /\left(\alpha_{\Gamma}+\beta\right)\right\}\right] /\left[\Pi_{\digamma=n}^{\lrcorner}\left\{\beta /\left(\alpha_{\Gamma}+\beta\right)\right\}\left\{\Sigma_{\sigma \cap}^{/} 1 / \beta_{\delta}\right\}\right]$.

Proof. The proof proceeds by construction. We shall use the fact that $E[$ time ecosystem functional $]$ $=E[$ time betwixt breakdowns $]-E[$ length breakdown period $]$. The probability of an ecosystem breakdown in a small time interval $(t, t+\Delta t)$ for large $t$ and a small increment $\Delta t$ essentially depends on the event in which a single keystone species is alive, all others are dead, and then this surviving species dies. All other events are irrelevant, because they collectively have probability $o(\Delta t)$, and $\lim _{\Delta \Theta \epsilon} o(\Delta t) / \Delta t=0$. Now applying Blackwell's theorem (see [25, p. 116] and [26, p. 110]) to this probability, we get $E[$ time betwixt period $]=1 /\left[\Pi_{\digamma=n}^{\lrcorner}\left\{\beta /\left(\alpha_{\digamma}+\beta\right)\right\}\left\{\Sigma_{\sigma n}^{/} 1 / \beta_{\delta}\right\}\right]$. It is clear that $E[$ length breakdown period $]=1 /\left[\Sigma_{\sigma \cap} 1 / \beta_{\varnothing}\right]$. Consequently, we conclude that ecosystem persistence is given by $E[$ time ecosystem functional $]=\left[1-\Pi_{\varpi \Theta}^{r}\left\{\beta_{\varpi}^{/}\left(\alpha_{\varpi}+\beta_{\varpi}\right)\right\}\right] /\left[\Pi_{\varpi \Theta}^{r}\left\{\beta_{\varpi}^{/}\left(\alpha_{\varpi}+\beta_{\varpi}\right)\right\}\left\{\Sigma_{\varkappa \Theta}^{r} 1 / \beta_{\varkappa}\right\}\right]$. 
The expression in the statement of Theorem 1 is our stochastic characterization of persistence. There are two things to note about this expression. First, our assumption of perfect substitutability between species in the performance of ecological functions notwithstanding, ecosystem persistence depends on all the keystone species. Second, we see that persistence depends on the means of the life and the death time distribution functions of the various keystone species in our ecosystem. This tells us that if we are able to estimate these parameters, then we will have an operational measure of the stability of an ecosystem.

Despite the significance of persistence, it is the notion of ecosystem resilience that has come to dominate much of the present center stage of academic debate about conservation related issues. Consequently, we now use the renewal theoretic framework of section 2 a to provide a mathematical characterization of this paper's second stability concept. This is the concept of an ecosystem's resilience.

\section{2c. Resilience}

Following most of the ecology literature — see [28, p. 587] and [29, p. 654]—on this subject, we shall think of resilience as a probability and as an asymptotic property of ecosystems. Our point of departure from this literature will lie in our conceptualization of resilience as a stochastic and not as a deterministic, asymptotic property. ${ }^{5}$ As such, our work complements previous work by Ives [23] on this subject. In particular, we shall show how resilience can be characterized by exploiting the mathematical links between persistence and resilience.

\footnotetext{
${ }^{5} \mathrm{~A}$ number of economists have studied the asymptotic stability of economic systems. In particular, Mitra and Wan [30] and Mitra et al. [4] have analyzed the asymptotic stability of deterministic models of forest management.
} 
Recall that resilience refers to the amount of disturbance that can be withstood by an ecosystem before a change in this ecosystem's control or structure occurs. In our modeling framework, disturbances are captured by the shocks to the ecosystem and by the death time distributions of the different species. Further, a change in an ecosystem's control or structure occurs when it breaks down. These two observations tell us that resilience can be thought of as the stationary probability that an ecosystem is functional. ${ }^{6}$ We can now state

Theorem 2. Ecosystem resilience is given by $\lim _{\left[{ }_{+\infty}\right.}$ Prob $\{$ ecosystem functional at time $t\}=$ $1-\Pi_{\square \square}^{\square}\left\{\beta /\left(\alpha_{\square}+\beta\right)\right\}$.

Proof. The proof proceeds by construction. From [26, p. 129] it follows that $\lim _{[+\infty}$ Prob $\{$ ecosystem functional at time $t\}=E[$ time ecosystem functional $] / E[$ time betwixt breakdowns $]$. Using the expressions for these two expectations from the proof of Theorem 1, we conclude that ecosystem resilience is given by $\lim _{\square_{+\infty}} \operatorname{Prob}\{$ ecosystem functional at time $t\}=1-\Pi_{\square \square}^{\square}\left\{\beta \measuredangle\left(\alpha_{\square}+\beta_{\square}\right)\right\}$.

Corollary. $\lim _{\text {tio }_{\infty}}$ Prob $\{$ ecosystem functional at time $t\} \propto E[$ time ecosystem functional $]$, and the constant of proportionality is given by $1 / E[$ time betwixt breakdowns].

\section{2d. Discussion}

The proof of Theorem 2 tells us that, like persistence, resilience also depends on all the keystone species in the ecosystem. Specifically, resilience depends on the means of the survival and the death time distribution functions. Note that, in general, the characteristics of the individual keystone species and the number of keystone species will collectively determine an ecosystem's persistence and its resilience. Having said this, one can still ask whether the individual species

${ }^{6}$ For an analysis of "stationary forests," the reader should consult Mitra and Wan [30]. 
characteristics - as measured by the $\alpha$ and the $\beta$ parameters—or the number of species is more important to maintaining the persistence and/or the resilience of an ecosystem. This is an open question that cannot be resolved by our renewal theoretic framework. ${ }^{7}$

To illustrate the results stated in Theorems 1 and 2, we now present two examples. Suppose that $m=3, \alpha_{i}=8, \forall i$, and that $\beta_{i}=4, \forall i$. If we measure time in years, then this means that the three keystone species in our ecosystem are alive for a mean time of eight years and then dead for a mean time of four years. Now using the expressions given in Theorems 1 and 2, we get 34.67 years as the numerical value for ecosystem persistence and 0.96 as the numerical value for ecosystem resilience. As an alternate example, suppose that $m=3, \alpha_{1}=1, \alpha_{2}=2, \alpha_{3}=3, \beta_{1}=8, \beta_{2}=9$, and $\beta_{3}=10$. Now the means of the survival and the death time distribution functions are different for the three keystone species of the ecosystem. Following the above-described procedure, the numerical value for ecosystem persistence is now 2.34 years and the numerical value for ecosystem resilience is 0.44 .

The reader will note that an implication of our renewal theoretic characterization of persistence and resilience is that these two stability concepts are completely determined by the means $\left(\alpha\right.$ and $\beta_{\text {至 }}$ of the life and the death time distribution functions. Put differently, other properties of these distribution functions do not affect an ecosystem's persistence or its resilience. In order to operationalize our measures of persistence and resilience, it will be necessary to obtain estimates of the means of the survival and the death time distribution functions, i.e., the $\alpha_{i}$ s and the $\beta_{i}$ s. Batabyal [17] and Krebs [28, pp. 164-5] discuss how survival and death rates can be calculated.

\footnotetext{
${ }^{7}$ As indicated in section 1, ecologists still debate the link between the number of species in an ecosystem and its stability. For more on this, see Tilman [11] and the references cited therein.
} 
In addition to this, as discussed in Krebs [28, pp. 180-1], methods used in the determination of ecological life tables are also likely to be useful in procuring estimates of the $\alpha_{i}$ s and the $\beta_{i}$.

The corollary to Theorem 2 tells us two important things about the connections between the two stability concepts that we have characterized in this paper and ecosystem management. First, we see that resilience is proportional to persistence. In other words, ecosystems that are very resilient are also those that are likely to be very persistent. From the perspective of ecosystem management, this tells us that managers whose goal is to make ecosystems resilient will need to focus on those factors that make ecosystems persistent.

Second, ecosystem resilience is inversely proportional to the expected length of time between ecosystem breakdowns. This feature also points to the role of management in promoting ecosystem resilience because the time between breakdowns corresponds in part to periods in which an ecosystem manager has taken preventive actions to protect species from the adverse effects of continued economic activity. As discussed in section 2a, these actions include things like regulations on the nature of fishing equipment, moratoriums on grazing, and the introduction of species. If all economic activities are terminated, then the expected length of a breakdown period — which will now depend exclusively on natural factors - will presumably have been made as short as possible. However, in most practical situations, such termination will not be a feasible course of action. In these situations, this analysis tells us that if ecosystem stability in the sense of resilience is to be enhanced, then managers will need to implement those policies which ensure that the expected length of a breakdown period is kept as short as possible. 


\section{CONCLUSIONS}

In this paper, we have argued that studies of the stability of ecosystems must be informed by the fact that such systems are jointly determined. Put differently, this means that the dynamics of the joint system reflect the nature of the connections between each of the two subsystems, i.e., the ecological and the economic subsystems. In particular, shocks to the joint system generate a set of ecological and a set of economic effects, and these effects are interlinked. We accounted for these aspects of the problem in three ways. First, we noted that shocks to the joint system make the life and the death times of the individual keystone species random. Second, we modeled the interlinked nature of the ecological and the economic effects by showing that the stability properties of the ecosystem under study depend on the means of both the life and the death time distribution functions. Third, we analyzed the evolution of our ecosystem by describing the ecosystem by means of an alternating renewal process. Our analysis led us to characterize ecosystem persistence as the expected amount of time during which this ecosystem is functional. We then focused on the asymptotic stability of our ecosystem. We showed that ecosystem resilience can be thought of as a stationary probability.

The analysis of this paper can be extended in a number of different directions. In what follows, we suggest two possible extensions. First, our characterizations of persistence and resilience depend on our assumptions about the life and the death time distribution functions, and on our independence assumption. Although these assumptions are somewhat strong, they are absolutely necessary for the analysis. In fact, our ongoing research on this subject leads us to conjecture that without some distributional assumption and without the independence assumption, the task of characterizing persistence and resilience is intractable. However, additional research is 
needed to determine whether this conjecture is true, and more generally, to determine the kinds of interactions between ecosystem species that can be studied in an analytically tractable manner.

Second, we are often interested in the short-term behavior of an ecosystem following shocks. The asymptotic notion of stability (resilience) that we have characterized in this paper focuses on the long-term behavior of an ecosystem; short-term, transient behavior is ignored. A useful extension of this paper would be to study ecosystem stability in a way that captures the short-term response of an ecosystem to perturbations.

Formal studies of ecosystem stability that incorporate these aspects of the problem into the analysis will provide richer and practically more relevant characterizations of ecosystem stability. Moreover, such studies are likely to provide useful guidance to individuals whose task is to mange stochastic ecosystems effectively. 


\section{REFERENCES}

1. Arrow, K. J., and L. Hurwicz. 1958. On the Stability of the Competitive Equilibrium I. Econometrica 26:522-52.

2. Hirota, M. 1985. Global Stability in a Class of Markets with Three Commodities and Three Consumers. Journal of Economic Theory 36:186-92.

3. Jordan, J. S. 1988. A Stability Problem With Nonstationary Overlapping Generations Equilibria. Journal of Economic Theory 45:425-33.

4. Mitra, T., D. Ray, and R. Roy. 1991. The Economics of Orchards: An Exercise in Point-Input, Flow-Output Capital Theory. Journal of Economic Theory 53:12-50.

5. Balasko, Y., and D. Royer. 1996. Stability of Competitive Equilibrium With Respect to Recursive and Learning Processes. Journal of Economic Theory 68:319-48.

6. Dasgupta, P. 1996. The Economics of the Environment. Environment and Development Economics 1:387-428.

7. Elton, C. S. 1958. The Ecology of Invasions by Animals and Plants. London, UK: Methuen.

8. McNaughton, S. J. 1977. Diversity and Stability of Ecological Communities: A Comment on the Role of Empiricism in Ecology. American Naturalist 111:515-25.

9. King, A. W., and S. L. Pimm. 1983. Complexity, Diversity, and Stability: A Reconciliation of Theoretical and Empirical Results. American Naturalist 122:229-39.

10. May, R. M. 1973. Stability and Complexity in Model Ecosystems. Princeton, NJ: Princeton University Press.

11. Tilman, D. 1996. Biodiversity: Population Versus Ecosystem Stability. Ecology 77: 350-63.

12. Perrings, C. 1996. Ecological Resilience in the Sustainability of Economic Development. In Models of Sustainable Development, S. Faucheux, D. Pearce, and J. Proops (eds.), Cheltenham, UK: Edward Elgar.

13. Pimm, S. L. 1991. The Balance of Nature? Chicago, IL: University of Chicago Press. 
14. Holling, C. S., D. Schindler, B. Walker, and J. Roughgarden. 1995. Biodiversity in the Functioning of Ecosystems: An Ecological Synthesis. In Biodiversity Loss, C. Perrings, K. Maler, C. Folke, C. S. Holling, and B. Jansson (eds.), Cambridge, UK: Cambridge University Press.

15. Perrings, C., K. Maler, C. Folke, C. S. Holling, and B. Jansson (eds.). 1995. Biodiversity Loss. Cambridge, UK: Cambridge University Press.

16. Batabyal, A. A. 1998. On Some Aspects of Ecological Resilience and the Conservation of Species. Journal of Environmental Management 52:373-8.

17. Batabyal, A. A. 1999. Species Substitutability, Resilience, and the Optimal Management of Ecological-Economic Systems. Mathematical and Computer Modelling 29:35-43.

18. Batabyal, A. A. 1998. The Concept of Resilience: Retrospect and Prospect. Environment and Development Economics 3:235-9.

19. Batabyal, A. A. 1999. Contemporary Research in Ecological Economics: Five Outstanding Issues. Unpublished manuscript, Utah State University.

20. DeAngelis, D. L., S. M. Bartell, and A. L. Brenkert. 1989. Effects of Nutrient Cycling and Food Chain Length on Resilience. American Naturalist 134:778-805.

21. Steinman, A. R., P. J. Mulholland, A. V. Palumbo, T. F. Flum, and D. L. DeAngelis. 1991. Resilience of Lotic Ecosystems to a Light-Elimination Disturbance. Ecology 72:1299-313.

22. Cottingham, K. L., and S. R. Carpenter. 1994. Predictive Indices of Ecosystem Resilience in Models of North Temperate Lakes. Ecology 75:2127-38.

23. Ives, A. R. 1995. Measuring Resilience in Stochastic Systems. Ecological Monographs 65:217-33.

24. Hahn, F. 1982. Stability. Vol. 2. In Handbook of Mathematical Economics, K. J. Arrow and M. D. Intriligator (eds.), Amsterdam, The Netherlands: North-Holland.

25. Wolff, R. W. 1989. Stochastic Modeling and the Theory of Queues. Englewood Cliffs, NJ: Prentice-Hall.

26. Ross, S. M. 1996. Stochastic Processes, 2nd ed. New York City, NY: Wiley.

27. Batabyal, A. A. 1998. An Ecological Economic Perspective on Resilience and the Conservation of Species. Unpublished manuscript. Logan, UT: Utah State University.

28. Krebs, C. J. 1985. Ecology, 3rd ed. New York City, NY: Harper and Row. 
29. Neubert, M. G., and H. Caswell. 1997. Alternatives to Resilience for Measuring the Responses of Ecological Systems to Perturbations. Ecology 78:653-65.

30. Mitra, T., and H. Y. Wan. 1986. On the Faustmann Solution to the Forest Management Problem. Journal of Economic Theory 40:229-49. 